\section{The underrepresentation and misrepresentation of invertebrates in the IUCN Red List}

Invertebrate conservation and management policies face a number of obstacles (Cardoso et al., 2011b). The red listing of species, i.e., the classification of species by threat category according to the International Union for the Conservation of Nature (IUCN) criteria, is one of the most useful tools for overcoming these impediments because it helps raise the awareness of invertebrate conservation problems and facilitates subsequent inclusion in lists of legally protected species (Cardoso et al., 2011b). However, the current IUCN criteria may not be optimal for invertebrates, and we have recently (Cardoso et al., 2011a; hereafter C\&A) offered suggestions for adapting the current criteria. Collen and Böhm (in press), (hereafter $C \& B$ ) replied, disagreeing with some of our arguments $(C \& A)$ and listing examples of invertebrate groups that have recently seen or are currently undergoing extensive evaluation.

Although we are aware that the representation of invertebrates in the IUCN Red List is increasing, the difficulty of applying the current criteria does not mean that these criteria cannot be applied in selected cases, and we applaud the current initiatives cited by C\&B. Although the 15,000 species mentioned are still $<2 \%$ of the described species and perhaps $0.1-1 \%$ of the extant species, these initiatives constitute significant progress, and we recognise that the IUCN is making a substantial effort to fill the gaps based on the available resources. However, most of the examples cited by C\&B (butterflies, cephalopods, crayfish, lobsters, dragonflies, dung beetles, freshwater crabs, freshwater molluscs and reef-building corals) are, with certain obvious exceptions, from relatively lowdiversity, large-bodied taxa with large distributional ranges and high dispersal ability. Most taxa, namely the hyperdiverse Coleoptera, Diptera, Hymenoptera, and other small-bodied organisms with restricted distributional ranges and low dispersal ability are in fact underrepresented. We argue that the lack of feasibility of the current criteria tends to promote underrepresentation and that the inadequacy of the criteria tends to promote misrepresentation of invertebrates.

Our first argument, regarding feasibility, is based on the difficulty of applying most of the current criteria using the information usually available for invertebrate species. In C\&A, we mention that most of the criteria are applicable only by indirect evidence, usually using the Area of Occupancy (AOO) or Extent of Occurrence (EOO) trends as surrogates of population abundance trends. A total of 1931 invertebrate species were evaluated since 2001 (when the current version 3.1 of the criteria was adopted) as Critically Endangered (CR), Endangered (EN) or Vulnerable (VU) and are currently red listed by IUCN (www.iucnredlist.org, accessed on 26.XII.2011). The majority of these species (62\%) received their status according to criterion B, $22 \%$ were classified under criterion D, $15 \%$ under A,
$0.4 \%$ under C and none under E. Criterion B is based on either AOO or EOO. Almost all species classified under criterion D were classified as Vulnerable, the only category in this criterion that uses AOO. Almost all species classified under criterion A (mostly corals) used indirect evidence from disappearing or degrading habitat, reflected in their AOO, and the assessors do recognise that no species-specific population information is available for most species. The lack of population abundance trend data is almost universal among invertebrates (e.g., 82\% of freshwater and 53\% of terrestrial European molluscs, http://data.iucn.org/dbtw-wpd/ edocs/RL-4-014.pdf). Using indirect evidence for abundance trends presents a number of problems and is not ideal (C\&A). Adapting most of the criteria to better reflect the data available, i.e., with the explicit use of AOO and EOO, would help to overcome such problems.

Our second argument, not considered by $C \& B$, refers to the adequacy of the current criteria. Both abundance and range thresholds may be inappropriate for most invertebrates. The extinction risk of species assessed with these thresholds may be either under or over-estimated, causing a misrepresentation (C\&A). Thus, the criteria should be modified to increase the adequacy of the classifications, although this adaptation is more difficult than the modifications required to address the feasibility problem.

It may be true, as argued by $C \& B$, that only a common set of criteria guarantees cross-taxon comparison and that long and complicated parameters and rules are not to be promoted. However, long and complicated rules are prevalent today, with the guidelines for the use of the IUCN Red List categories and criteria covering dozens of pages (http://www.iucnredlist.org/documents/ RedListGuidelines.pdf). Our proposal is to simplify the rules so that they can be more easily and effectively applied to a wider range of taxa. The IUCN Red List system has made substantial progress since it was first conceived, and it has overcome major obstacles and deficiencies. However, we argue that the problems of underrepresentation and misrepresentation could be approached more effectively and more rapidly by recognising the current deficiencies in feasibility and adequacy and by adopting a focus that specifically addresses these shortfalls, and we hope that our current and future work contributes towards this goal.

\section{References}

Cardoso, P., Borges, P.A.V., Triantis, K.A., Ferrández, M.A., Martín, J.L., 2011a. Adapting the IUCN Red List criteria for invertebrates. Biol. Conserv. 144, 24322440 .

Cardoso, P., Erwin, T.L., Borges, P.A.V., New, T.R., 2011b. The seven impediments in invertebrate conservation and how to overcome them. Biol. Conserv. 144, 2647-2655.

Collen, B., Böhm, M., 2012. The growing availability of invertebrate extinction risk assessments. Biol. Conserv. in press. 
Pedro Cardoso ${ }^{\mathrm{a}, \mathrm{b}, *}$

Paulo A.V. Borges ${ }^{b}$

Kostas A. Triantis ${ }^{\text {b,c }}$

Miguel A. Ferrández ${ }^{\mathrm{d}}$

José L. Martín ${ }^{\mathrm{e}}$

a Smithsonian Institution, National Museum of Natural History,

Washington, DC, USA

${ }^{\mathrm{b}}$ Azorean Biodiversity Group (CITA-A), University of the Azores, Angra do Heroísmo, Portugal

${ }^{\mathrm{c}}$ Department of Ecology and Taxonomy, Faculty of Biology, National and Kapodistrian University of Athens, Athens, Greece

${ }^{\mathrm{d}}$ Society for the Study and Conservation of Spiders, Madrid, Spain

${ }^{\mathrm{e}}$ The Canary Agency for Sustainable Development and Climate Change, Santa Cruz de Tenerife, Canary Islands, Spain * Corresponding author. Address: Azorean Biodiversity Group (CITA-A), Universidade dos Açores, Rua Capitão João d'Ávila,

9700-042 Angra do Heroísmo, Portugal

Tel.: +351 295402 200; fax: +351295 402205 .

E-mail address: pcardoso@ennor.org (P. Cardoso)

Available online 24 March 2012 